\title{
Chromosomal Abnormalities Associated With Local Recurrence or Pulmonary Metastasis of Giant Cell Tumor of Bone in Thai Adults: A Prospective Cohort Study With 6 Years of Follow-Up
}

Pakpoom Ruangsomboon

Siriraj Hospital

Worapa Heepchantree

Siriraj Hospital

Pissanu Reingrittha

Buddhachinaraj Hospital

Saranatra Waikakul

Mahidol University

Rapin Phimolsarnti ( $\sim$ rapin.phi@mahidol.edu )

Mahidol University

\section{Research Article}

Keywords: Chromosomal abnormalities, local recurrence, pulmonary metastasis, giant cell tumor of bone, Thai adults

Posted Date: June 10th, 2021

DOl: https://doi.org/10.21203/rs.3.rs-538122/v1

License: (c) (1) This work is licensed under a Creative Commons Attribution 4.0 International License.

Read Full License 


\section{Abstract}

Background: Giant cell tumor (GCT) of bone demonstrates chromosomal abnormalities. This study aimed to investigate the prognostic role of chromosomal abnormalities of primary GCT of bone relative to local recurrence or pulmonary metastasis.

Methods: This prospective longitudinal cohort study with 6 years of follow-up included consecutive patients with primary GCT of bone that were surgically treated during 2011 to 2013 at the Department of Orthopaedic Surgery, Faculty of Medicine Siriraj Hospital, Mahidol University, Bangkok, Thailand. All patients underwent surgical resection with extended intralesional curettage and phenol local adjuvant therapy. Systematic cytogenetic analysis compared cytogenetic abnormalities between patients with and without local recurrence or pulmonary metastasis. Fifteen patients were eligible, enrolled, and had successful cytogenetic analysis.

Results: The median follow-up time was 46 months (interquartile range [IQR]: 32-58). Five patients experienced local recurrence or pulmonary metastasis with a median time to recurrence of 6 months (IQR: 3.25-10.5). The mean number of abnormal cells in the primary culture compared between those with local recurrence or pulmonary metastasis and those without was $24.4 v s$. 9.6 cells, respectively $(p=0.04)$. A similar pattern was observed in the cultures of the subsequent four passages (all $p<0.05$ ). Forty-five patterns of clonal telomeric association (tas) were observed in passaged cultures. Six tas patterns were associated with local recurrence or pulmonary metastasis, including tas $(11 ; 19)(p 15 ; q 13.4)$, tas $(15 ; 19)$ (q26.3;q13.4), tas(15;22)(p13;p13), tas(16;19)(p13.3;q13.4), tas(17;19)(p13;q13.4), and tas(19;22) (q13.4; q13).

Conclusions: The mean number of abnormal cells and the six identified TAS patterns may be valuable prognostic factors for local recurrence or pulmonary metastasis of GCT tumor of bone.

\section{Background}

Giant cell tumor (GCT) of bone is the most common benign aggressive tumor of bone. The incidence of this tumor in Asian population is approximately $15 \%$ [1-4], and postoperative recurrence rates ranging from $18-65 \%$ have been reported [5-7]. The recurrence rate is approximately $17.4 \%$ within the first five years of follow-up [8]. Intralesional curettage with the subsequent application of different adjuvant substances to control local recurrence of GCT of bone have been studied, including warm Ringer's lactate solution, phenol, bone cement, zoledronic acid-loaded bone cement, and liquid nitrogen [9-12].

Campanacci, et al. reported the presence of tumor at the surgical margin to be the prognostic factor that most strongly predicts recurrent GCT [13]. Other potential predictors have been extensively studied; however, radiographic findings, histologic appearance, and immune-histochemical stain, such as Ki-67, were not able to predict local aggressiveness and/or the metastatic potential of the tumor after surgery [14-19]. Conversely, abnormalities found in genetic studies of DNA or chromosomal study of the tumor were strongly associated with local recurrence and lung metastasis [20-23]. Bridge, et al. found 
chromosomal abnormalities in GCT of bone, particularly telomeric fusion. As a consequence of that finding, cytogenetic analysis has been suggested as a potentially useful tool for predicting the aggressiveness of a tumor [24]. However, few cytogenetic studies have been reported to date.

Accordingly, the aim of this study was to identify chromosome abnormalities in GCT of bone that are significantly associated with the primary outcomes of our study by subjecting tissue taken from primary lesions to cytogenetic analysis and then comparing cytogenetic abnormalities between patients with and without local recurrence or pulmonary metastasis.

\section{Methods}

This prospective longitudinal cohort study with 6 years of follow-up included consecutive patients with primary GCT of bone that were surgically treated during 2011 to 2013 at the Division of Orthopaedic Oncology of the Department of Orthopaedic Surgery, Faculty of Medicine Siriraj Hospital, Mahidol University, Bangkok, Thailand. The Siriraj Institutional Review Board (SIRB) approved our study protocol (COA no. 418/2556 (EC4)), and all patients provided written informed consent to participate. All methods were carried out in accordance with relevant guidelines and regulations.

Complete history, physical examination, and imaging investigations, including plain radiograph at the lesion, plain radiograph of the chest (posteroanterior and lateral views), computed tomography (CT) chest, bone scan, and magnetic resonance imaging/CT scan at the lesion, were performed in all patients. Open biopsy was performed for definite diagnosis in all patients. If the pathological diagnosis was conventional GCT of bone, the patient was enrolled in the study. Demographic and clinical data, including age, gender, location of the tumor (axial/nonaxial skeleton), and preoperative Campanacci GCT tumor classification, were recorded in all patients. All patients then underwent definitive treatment using extended intralesional curettage, and 1 cubic $\mathrm{mm}$ of the solid parts of the tumor was sent for cytogenetic study. The primary tumor tissues derived intraoperatively were added into sterile tubes containing fetal bovine serum cell culture media, and then they were immediately transferred to our cytogenetic laboratory. Local treatment with high-speed burr, electrocautery, and phenol was performed, and bone cement was used to fill the bony lesions. After surgery, patients were followed-up every month during the first year, and then every three months after that for six years consistent with routine practice at our center. The outcome was a composite of local recurrence or pulmonary metastasis. Preoperative clinical presentation of the primary tumor, and postoperative presentation of the locally recurrent tumor or pulmonary metastasis was recorded in all patients.

\section{Cytogenetic procedure}

The cytogenetic study was conducted at the Cytogenetic Laboratory for Leukemia Diagnosis, Research Department, Faculty of Medicine Siriraj Hospital, Mahidol University. This laboratory is ISO 15189 and ISO 15190 accredited. Cytogenetic investigators were blinded to the clinical presentations. Primary tumor tissues were obtained during the operation and placed into Dulbecco's Modified Eagle Medium (DMEM) (Gibco; Sigma-Aldrich Corporation, St. Louis, MO, USA) with antibiotics (Biochrom AG, Berlin Germany). 
The specimens were subsequently mechanically disaggregated by mincing with a scalpel blade, and enzymatically by incubation in collagenase (Biochrom AG). Short-term culture was performed following the Mandahl protocol. After removal of the collagenase solution, the cells were resuspended in DMEM with $20 \%$ fetal calf serum. The cultures were placed in a humidified $37^{\circ} \mathrm{C}, 5 \% \mathrm{CO}_{2}$ incubator. After $10-14$ days of cultivation, the cells were in log phase. Three hours before harvesting, the cells were exposed to colchicine $(0.25 \mu \mathrm{g} / \mathrm{mL})$. The cell suspension was then resuspended in $\mathrm{KCl}$ Solution (hypotonic) $0.075 \mathrm{M}$ (Sigma-Aldrich) twice, and then fixed three times with a 3:1 mixture of methanol and acetic acid. The cell suspension was dropped on slides, and Q-banding was performed. Serial passaging was then performed on the cultures of all patients to study the dynamics of chromosome changes in GCT of bone. The culture conditions were as previously described, and the cell cultures were split 1:2 at subconfluency. The samples were studied from primary culture to five passages [25]. The 50 metaphases in every passage were analyzed according to the International System for Human Cytogenetic Nomenclature 2013. The number of abnormal cells and the total number of abnormalities and types of abnormalities, including numerical, structural, and telomeric association, were recorded. Association of the short arm of the acrocentric chromosome was also recorded as telomeric association. Nonclonal and clonal chromosome changes, and the frequencies of the telomerase associations were calculated.

\section{Study size and statistical analysis}

An a priori sample size was calculated for this study. All eligible patients were included. Categorical variables are presented as frequency and percentage, and normally distributed continuous variables are given as mean plus/minus standard deviation. Unpaired $t$ test was used to compare the means of the local recurrence or pulmonary metastasis group with the group that didn't have either of those outcomes. A $p$-value of less than 0.05 was considered statistically significant, and all data analyses were performed using SPSS Statistics version 18 (SPSS, Inc., Chicago, IL, USA).

\section{Results}

A total of 15 patients were screened for eligibility and enrolled. No patients were lost to follow-up or died during the study period. All participants completed the study protocol, including successful cytogenetic analysis. Patient demographic and clinical characteristics are shown in Table 1. The mean age of included patients was 35.4 years. Of the 15 included patients, 10 (66.7\%) were female. Most of our GCT cohort had non-axial skeletal involvement (86.6\%) and Campanacci stage 2 (66.7\%). There was only one case $(6.7 \%)$ of confirmed pulmonary metastasis prior to operation. Five patients $(33.3 \%)$ had either local recurrence or pulmonary metastasis during the 6-year postoperative follow-up period. The mean number of abnormal cells in the primary culture of patients with either study outcome of interest was significantly higher than in those without ( $24.4 v s .9 .6$ cells, respectively; $p=0.04$ ). Similar patterns were found in subsequent cultures for four passages $(p<0.05)$ (Table 2$)$. Forty-five patterns of clonal telomeric association (tas) were observed in passaged cultures; however, only six patterns, including tas $(11 ; 19)$ (p15;q13.4), tas(15;19)(q26.3;q13.4), tas(15;22)(p13;p13), tas(16;19)(p13.3;q13.4), tas(17;19)(p13;q13.4), and tas(19;22)(q13.4;q13), were consistently found in the cultured samples from primary GCT of bone 
from patients with recurrence (Figures 1-6). Similar abnormal observations were found in all passaged cultures.

\section{Discussion}

Prediction of local recurrence or pulmonary metastasis of GCT of bone after surgery is a major challenge for orthopedic oncology surgeons. The recurrence rate of GCT and/or pulmonary metastasis was reported to range from $0 \%$ to $4 \%$ [26-30]. Early detection of patients at high risk for recurrence would improve outcomes; however, a proven and accepted list of independent predictive factors has not yet been established. Some predictors of recurrent GCT of bone have been explored and reported, including serum alkaline phosphatase, serum calcium, serum phosphate, serum vitamin D level, and bone mineral [14-23], yet none of these are used in clinical practice. Some centers use Campanacci staging, which is a system that was designed to stage only GCT [13]. Gorunova, et al. suggested that local recurrence probably depends more on the adequacy of surgical treatment than on the intrinsic biology of the tumors [32]. In contrast, other authors proposed that the intrinsic biology of the tumors, such as DNA, may be associated with the recurrence of GCT of bone [33-35]. Jeffrey, et al. found telomeric association and del(11)(p11) to have strong association with local recurrence of GCT of bone [36]. Bridge, et al. also stated that telomeric fusion and cytogenetic analysis might be useful in predicting the biologic behavior of GCT of bone [24]. Therefore, the present study was conducted with cytogenetic study to identify chromosomal abnormalities that may predict recurrent GCT of bone.

The results of the cytogenetic analysis in the present study showed a significantly higher number of abnormal cells in the recurrent group compared with the nonrecurrent group. This finding could be clearly established at the primary culture or the first passage of the tumor. Furthermore, we found six consistent patterns of cytogenetic abnormality only in our recurrent cases. The cytogenetic analysis results were also similar in the later passages (the second to fifth passages of the DNA culture). The duration of each passage was approximately 1 week to cytogenetically analyze the aggressiveness of the tumor. These findings are very important because the mean number of cells in the primary culture was adequate for identifying the aggressiveness of the intrinsic tumor biology. The results of this study provide credible evidence that cytogenetic analysis may be a dependable method for predicting the likelihood of tumor recurrence in GCT of bone. Our study had a similar result to that of Unni, et al. who reported the most common abnormal karyotypic finding in recurrence of GCT of bone to be tas $11 p, 15 p, 19 q$ and $21 p[36]$.

\section{Limitations}

This study has some mentionable limitations. First, this study may have been limited by interobserver variation during the cytogenetic study due to the high technical skill required. Second, we did not conduct a genome sequencing study because it is necessary that we identify chromosomal abnormalities via cytologic study first. Third, the sample size was small, so adjustment for confounding factors or prognostic modeling could not be performed. Fourth and last, the patients that were enrolled in this study 
were recruited from a single center. The strength of this study is its prospective longitudinal cohort design with a 6-year follow-up period.

\section{Conclusion}

The mean number of abnormal cells and six tas patterns, including tas $(11 ; 19)(p 15 ; q 13.4)$, tas $(15 ; 19)$ (q26.3;q13.4), tas(15;22)(p13;p13), tas(16;19)(p13.3;q13.4), tas(17;19)(p13;q13.4), and tas(19;22) (q13.4;q13), from cytogenetic analysis of GCT of bone primary tumor tissue were found to be significantly associated with local recurrence or pulmonary metastasis during 6 years of follow-up. A prospective multi-center study in a larger number of GCT patients is needed to confirm the value of these factors as predictors of local recurrence or pulmonary metastasis in GCT of bone.

\section{Declarations}

\section{Funding disclosure}

This study was entirely funded by the Prasert Prasarttong-O-Soth Fund via the Medical Association of Thailand

- Conflict of Interest: The authors declare that they have no conflict of interest.

- Availability of data and material: not applicable

- This study was approved by Siriraj Institutional Review Board (SIRB).

- Ethical approval: This study included human participants. It had been approved by Siriraj Institutional ((COA no. 418/2556 (EC4))

- All methods were carried out in accordance with relevant guidelines and regulations.

- This study was retrospectively registered at gov (TCTR20210427003)

- Consent to participate: Informed consent was obtained from all individual participants included in the study.

- Consent for publication: All authors have read and approved the final submitted manuscript.

\section{Authors' contributions:}

Pakpoom Ruangsomboon and Rapin Phimolsarnti provided research questions, conducted data collection, analyzed data, discussion and developed the full manuscript. Worapa Heepchantree, PhD. And Pissanu Reingrittha, MD examined all data analysis, detailed the results, statistical calculation and collected and monitored data. Saranatra Waikakul, MD also provided the research question and useful advice

\section{Conflict of interest declaration}


All authors declare no personal or professional conflicts of interest, and no financial support from the companies that produce and/or distribute the drugs, devices, or materials described in this report.

\section{Availability of data and material}

The datasets used and/or analysed during the current study available from the corresponding author on reasonable request.

\section{Consent for publication}

All authors have read and approved the final version of the manuscript, and all authors agree with the decision to submit this manuscript for journal publication.

\section{Acknowledgements}

The authors gratefully acknowledge the patients that generously agreed to participate in this study, and Wachirapan Narktang, B.Sc, M.Sc. (Applied statistics) for assistance with statistical analysis. We thank Mrs. Thanyawan Aresanasuwan for her support in collecting the samples. We thank Dr. Onlak Ruangsomboon, MD, Dr. Anthony Tan, MD and Kevin Jones for their assistance in editing the manuscript.

\section{Conflict of interest declaration}

All authors declare no personal or professional conflicts of interest, and no financial support from the companies that produce and/or distribute the drugs, devices, or materials described in this report.

\section{References}

1. Pongkripetch M, Sirikulchayanonta V. 1989. Analysis of bone tumors in Ramathibodi Hospital, Thailand during 1977-1986: study of 652 cases. J Med Assoc Thai 72: 621-628.

2. Settakorn J, Lekawanvijit S, Arpornchayanon O, et al. 2006. Spectrum of bone tumors in Chiang Mai University Hospital, Thailand according to WHO classification 2002: A study of 1,001 cases. J Med Assoc Thai 89: 780-787.

3. Liede A, Hernandez RK, Tang ET, Li C, Bennett B, Wong SS, Jandial D. Epidemiology of benign giant cell tumor of bone in the Chinese population. J Bone Oncol. 2018 Jul 26;12:96-100.

4. Cao H, Lin F, Hu Y, et al. 2017. Epidemiological and Clinical Features of Primary Giant Cell Tumors of the Distal Radium: A Multicenter Retrospective Study in China. Sci Rep 7: 9067.

5. Errani C, Ruggieri P, Asenzio MA, Toscano A, Colangeli S, Rimondi E, Rossi G, Longhi A, Mercuri M. Giant cell tumor of the extremity: A review of 349 cases from a single institution. Cancer Treat Rev. 2010 Feb;36(1):1-7.

6. Karpik M. Giant Cell Tumor (tumor gigantocellularis, osteoclastoma) - epidemiology, diagnosis, treatment. Ortop Traumatol Rehabil. 2010 May-Jun;12(3):207 - 15. 
7. Klenke, F. M., Wenger, D. E., Inwards, C. Y., Rose, P. S. \& Sim, F. H. Giant cell tumor of bone: risk factors for recurrence. Clin Onhop Relat Res. 469, 591-599 (2011).

8. Hasan O, Ali M, Mustafa M, Ali A, Umer M. Treatment and recurrence of giant cell tumors of bone - A retrospective cohort from a developing country. Ann Med Surg (Lond). 2019;48:29-34.

9. Robinson D, Yassin M, Nevo Z. 2004. Cryotherapy of musculoskeletal tumors-from basic science to clinical results. Technol Cancer Res Treat 3: 371-375.

10. van der Heijden L, van der Geest IC, Schreuder HW, et al. 2014. Liquid nitrogen or phenolization for giant cell tumor of bone?: a comparative cohort study of various standard treatments at two tertiary referral centers. J Bone Joint Surg Am 96: e35.

11. Chen KH, Wu PK, Chen CF, et al. 2015. Zoledronic acid-loaded bone cement as a local adjuvant therapy for giant cell tumor of the sacrum after intralesional curettage. Eur Spine J 24: 2182-2188.

12. Waikakul S, Asavamongkolkul A, Phimolsarnti R. 2016. Use of warm Ringer's lactate solution in the management of locally advanced giant cell tumor of bone. Int J Clin Oncol 21: 177-185.

13. Campanacci M, Baldini N, Boriani S, et al. 1987. Giant-cell tumor of bone. J Bone Joint Surg Am 69: 106-114.

14. Rousseau MA, Handra-Luca A, Lazennec JY, et al. 2004. Metachronous multicentric giant-cell tumor of the bone in the lower limb. Case report and Ki-67 immunohistochemistry study. Virchows Arch 445: 79-82.

15. Balke M, Schremper L, Gebert C, et al. 2008. Giant cell tumor of bone: treatment and outcome of 214 cases. J Cancer Res Clin Oncol 134: 969-978.

16. Gupta R, Seethalakshmi V, Jambhekar NA, et al. 2008. Clinicopathologic profile of 470 giant cell tumors of bone from a cancer hospital in western India. Ann Diagn Pathol 12: 239-248.

17. Ismail FW, Shamsudin AM, Wan Z, et al. 2010. Ki-67 immuno-histochemistry index in stage III giant cell tumor of the bone. J Exp Clin Cancer Res 29: 25.

18. Chanchairujira K, Jiranantanakorn T, Phimolsarnti R, et al. 2011. Factors of local recurrence of giant cell tumor of long bone after treatment: plain radiographs, pathology and surgical procedures. $\mathrm{J}$ Med Assoc Thai 94: 1230-1237.

19. He Y, Wang J, Zhang J, et al. 2017. A prospective study on predicting local recurrence of giant cell tumour of bone by evaluating preoperative imaging features of the tumour around the knee joint. Radiol Med 122: 546-555.

20. Papanastassiou I, loannou M, Papagelopoulos PJ, et al. 2010. P53 expression as a prognostic marker in giant cell tumor of bone: a pilot study. Orthopedics 33.

21. Saito T, Mitomi H, Suehara Y, et al. 2011. A case of de novo secondary malignant giant-cell tumor of bone with loss of heterozygosity of p53 gene that transformed within a short-term follow-up. Pathol Res Pract 207: 664-669.

22. Okubo T, Saito T, Mitomi H, et al. 2013. p53 mutations may be involved in malignant transformation of giant cell tumor of bone through interaction with GPX1. Virchows Arch 463: 67-77. 
23. Zhang K, Zhou M, Chen H, et al. 2015. Expression of IMP3 and IGF2 in giant cell tumor of spine is associated with tumor recurrence and angiogenesis. Clin Transl Oncol 17: 570-575.

24. Bridge JA, Neff JR, Bhatia PS, et al. 1990. Cytogenetic findings and biologic behavior of giant cell tumors of bone. Cancer 65: 2697-2703.

25. atcc.org [Internet]. Manassas: American Type Culture Collection; Technical Bulletin no.6, Reference Strains: How many passages are too many? [Updated 2014 Mar 27; cited 2020 Nov 20]

26. Bertoni F, Present D, Sudanese A, et al. 1988. Giant-cell tumor of bone with pulmonary metastases. Six case reports and a review of the literature. Clin Orthop Relat Res: 275-285.

27. Cheng JC, Johnston JO. 1997. Giant cell tumor of bone. Prognosis and treatment of pulmonary metastases. Clin Orthop Relat Res: 205-214.

28. Dominkus $M$, Ruggieri $P$, Bertoni $F$, et al. 2006. Histologically verified lung metastases in benign giant cell tumours-14 cases from a single institution. Int Orthop 30: 499-504.

29. Errani C, Ruggieri P, Asenzio MA, et al. 2010. Giant cell tumor of the extremity: A review of 349 cases from a single institution. Cancer Treat Rev 36: 1-7.

30. Klenke FM, Wenger DE, Inwards CY, et al. 2011. Giant cell tumor of bone: risk factors for recurrence. Clin Orthop Relat Res 469: 591-599.

31. Gorunova L, Vult von Steyern F, Storlazzi CT, et al. 2009. Cytogenetic analysis of 101 giant cell tumors of bone: nonrandom patterns of telomeric associations and other structural aberrations. Genes Chromosomes Cancer 48: 583-602.

32. Zheng MH, Siu P, Papadimitriou JM, et al. 1999. Telomeric fusion is a major cytogenetic aberration of giant cell tumors of bone. Pathology 31: 373-378.

33. Garcia JL, Robledo C, Lumbreras E, et al. 2006. Analysis of chromosomal imbalances in an elderly woman with a giant cell tumour. Virchows Arch 448: 95-99.

34. Forsyth RG, De Boeck G, Bekaert S, et al. 2008. Telomere biology in giant cell tumour of bone. J Pathol 214: 555-563.

35. Sawyer JR, Goosen LS, Binz RL, et al. 2005. Evidence for telomeric fusions as a mechanism for recurring structural aberrations of chromosome 11 in giant cell tumor of bone. Cancer Genet Cytogenet 159: 32-36.

36. Unni KK. 1996. Dahlin's bone tumor: general aspect and data on 11,087 cases. 5th ed. Philadelphia: Lippincott-Raven;

\section{Tables}

Table 1. Patient demographic and clinical characteristics ( $N=15)$ 


\begin{tabular}{|c|c|}
\hline Characteristics & Value \\
\hline Age (years), mean $\pm S D$ & $35.4 \pm 14.8$ \\
\hline \multicolumn{2}{|l|}{ Gender, n (\%) } \\
\hline Female & $10(66.7 \%)$ \\
\hline Male & $5(33.3 \%)$ \\
\hline Non-recurrent GCT, n (\%) & $10(66.7 \%)$ \\
\hline Recurrent GCT or pulmonary metastasis, n (\%) & $5(33.3 \%)$ \\
\hline \multicolumn{2}{|l|}{ Location of involvement, $\mathrm{n}(\%)$} \\
\hline - $\quad$ Non-axial skeleton & $13(86.6 \%)$ \\
\hline - $\quad$ Axial skeleton & $2(13.4 \%)$ \\
\hline - $\quad$ Both & $0(0.0 \%)$ \\
\hline \multicolumn{2}{|l|}{ Campanacci staging, $\mathrm{n}(\%)$} \\
\hline-0 & $0(0.0 \%)$ \\
\hline-1 & $5(33.3 \%)$ \\
\hline-2 & $10(66.7 \%)$ \\
\hline-3 & $0(0.0 \%)$ \\
\hline \multicolumn{2}{|c|}{ Tumor recurrence or pulmonary metastasis before operation, $\mathrm{n}(\%)$} \\
\hline - Yes & $1(6.7 \%)$ \\
\hline - No & $14(93.3 \%)$ \\
\hline \multicolumn{2}{|c|}{ Tumor recurrence or pulmonary metastasis after operation, $\mathrm{n}(\%)$} \\
\hline - Yes & $5(33.3 \%)$ \\
\hline - No & $10(66.7 \%)$ \\
\hline
\end{tabular}

Abbreviations: SD, standard deviation; GCT, giant cell cancer

Table 2. Number of aberrant cells along 5 passages of culture compared between the non-recurrent and recurrent groups 


\begin{tabular}{|c|c|c|c|}
\hline \multicolumn{2}{|c|}{$\begin{array}{l}\text { Sequence of cytological culture / } \\
\text { classification ( } n)\end{array}$} & \multirow{2}{*}{$\begin{array}{l}\text { Number of aberrant cells } \\
\text { (mean } \pm \text { SD) } \\
6.90 \pm 6.67\end{array}$} & \multirow{2}{*}{$\begin{array}{l}p \text {-value } \\
\text { (95\% Cl of the difference) } \\
0.002\end{array}$} \\
\hline Passage 1 & - Non-recurrent $(n=10)$ & & \\
\hline (primary culture) & - Recurrent $(n=5)$ & $22.40 \pm 6.27$ & $(-23.50$ to -7.50$)$ \\
\hline \multirow[t]{2}{*}{ Passage 2} & - Non-recurrent $(n=10)$ & $5.90 \pm 6.01$ & 0.003 \\
\hline & - Recurrent $(n=5)$ & $24.00 \pm 7.91$ & $(-27.77$ to -8.43$)$ \\
\hline \multirow[t]{2}{*}{ Passage 3} & - Non-recurrent $(n=10)$ & $6.20 \pm 6.03$ & $<0.001$ \\
\hline & - Recurrent $(n=5)$ & $27.00 \pm 4.36$ & $(-26.81$ to -14.79$)$ \\
\hline \multirow[t]{2}{*}{ Passage 4} & - Non-recurrent $(n=10)$ & $8.20 \pm 7.73$ & 0.001 \\
\hline & - Recurrent $(n=5)$ & $27.20 \pm 6.83$ & $(-27.83$ to -10.16$)$ \\
\hline \multirow[t]{2}{*}{ Passage 5} & - Non-recurrent $(n=10)$ & $7.80 \pm 7.86$ & 0.002 \\
\hline & - Recurrent $(n=5)$ & $31.00 \pm 9.62$ & $(-35.02$ to -11.37$)$ \\
\hline \multicolumn{4}{|c|}{ A $p$-value $<0.05$ indicates statistical significance (independent samples $t$-test) } \\
\hline \multicolumn{4}{|c|}{ Abbreviations: SD, standard deviation; $\mathrm{Cl}$, confidence interval } \\
\hline
\end{tabular}

\section{Figures}




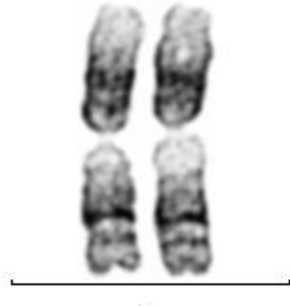

1
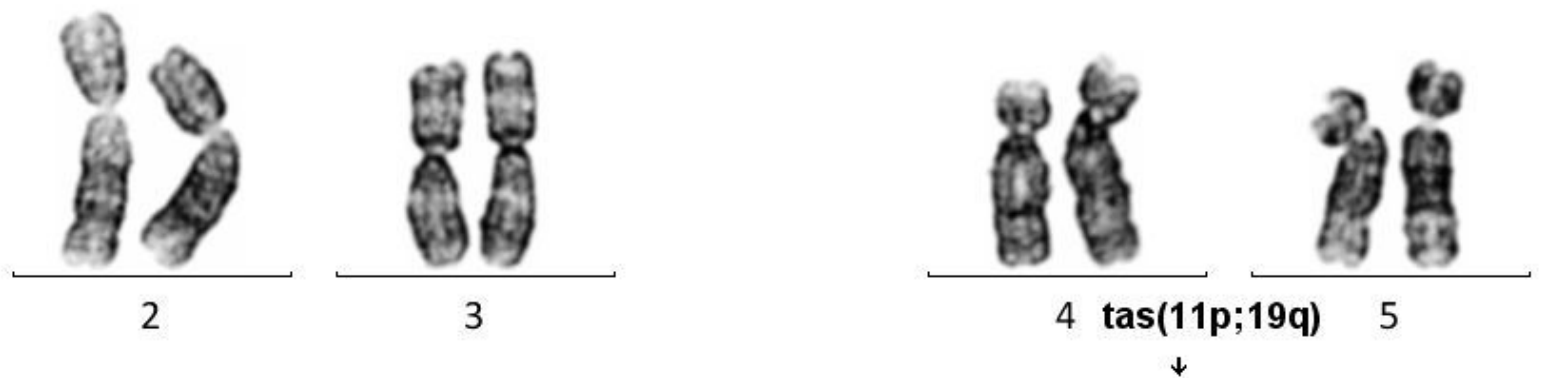

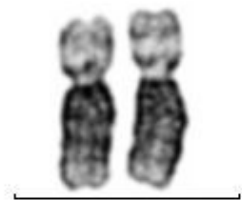

6

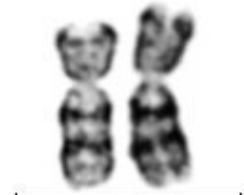

7

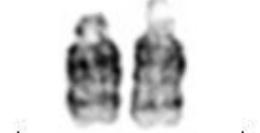

14

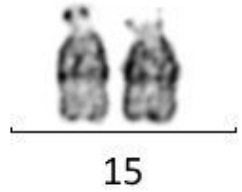

13

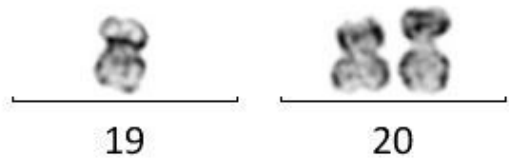

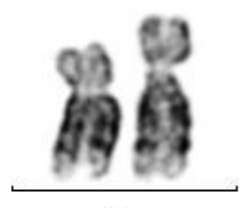

8

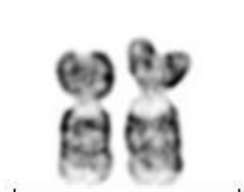

9

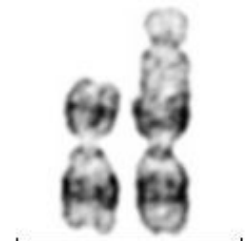

11

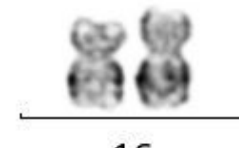

16

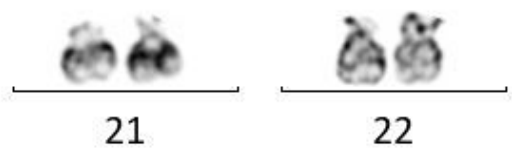

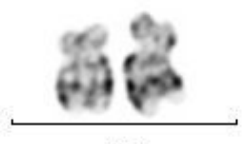

17

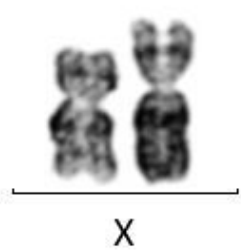

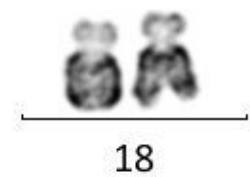

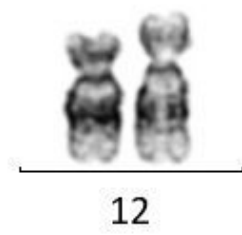

18

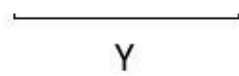

Figure 1

Telomeric association (tas) pattern $(11 ; 19)(\mathrm{p} 15 ; \mathrm{q} 13.4)$ 

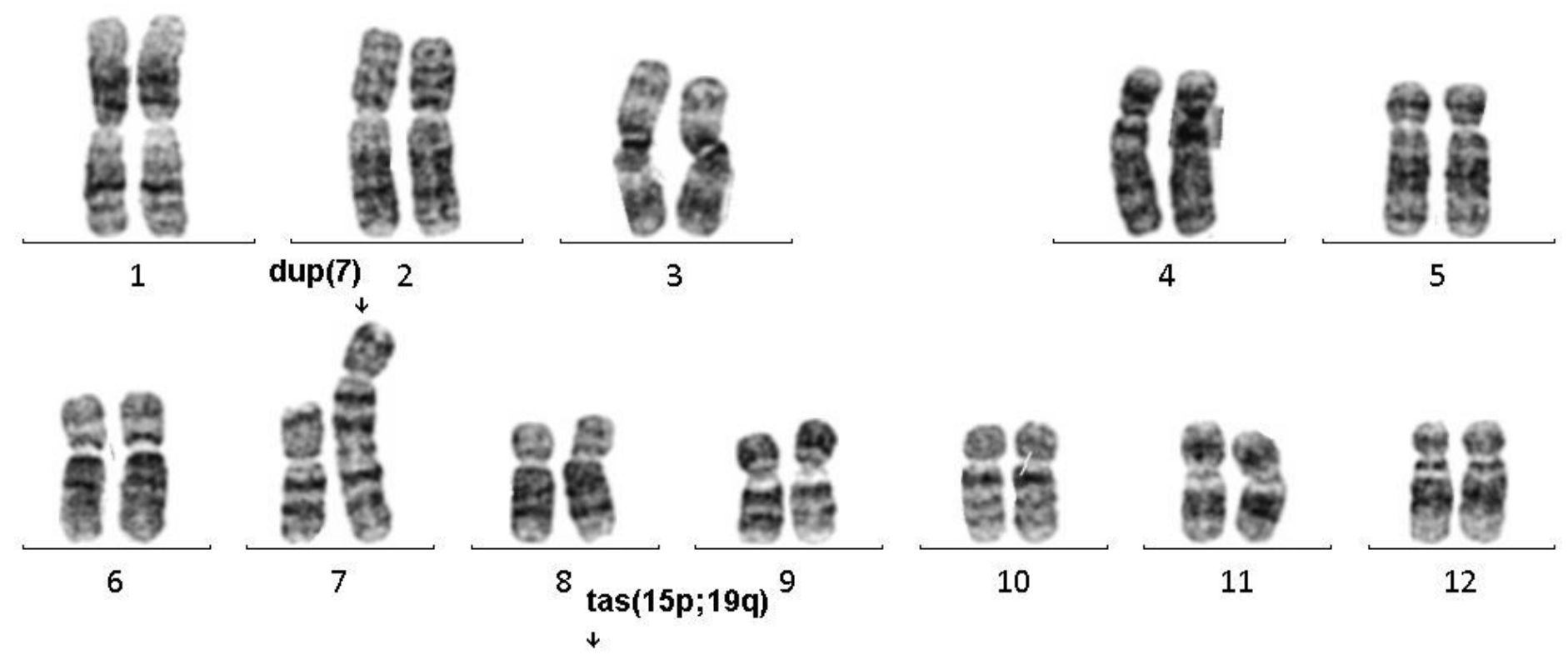

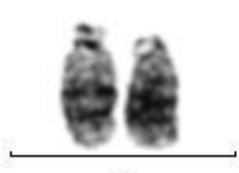

13

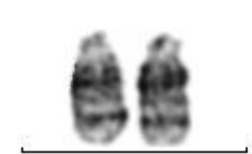

14

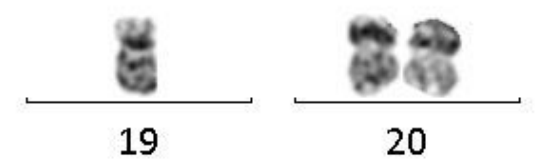

15
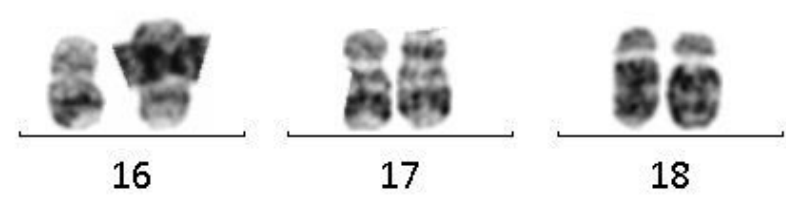

Figure 2
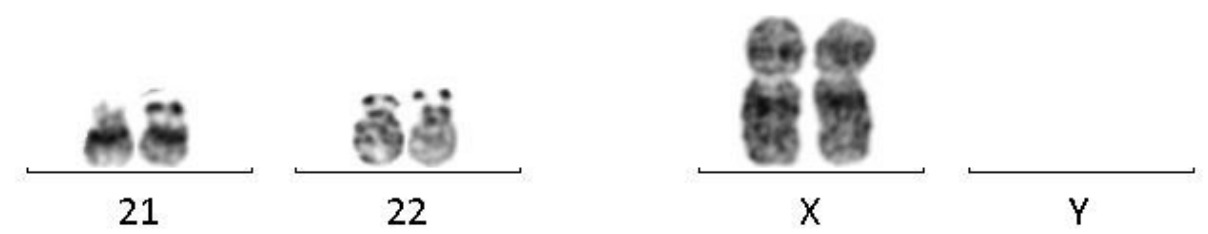

Telomeric association (tas) pattern (15;19)(q26.3;q13.4) 


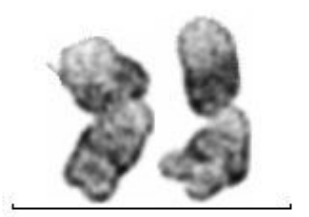

1

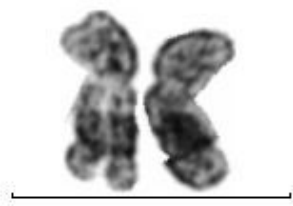

2

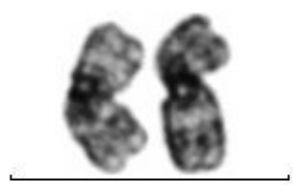

3

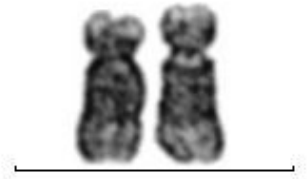

4

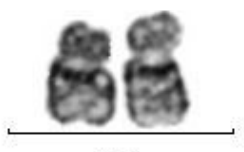

10

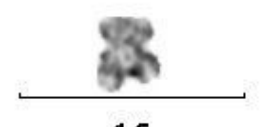

16
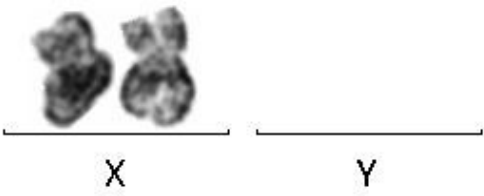
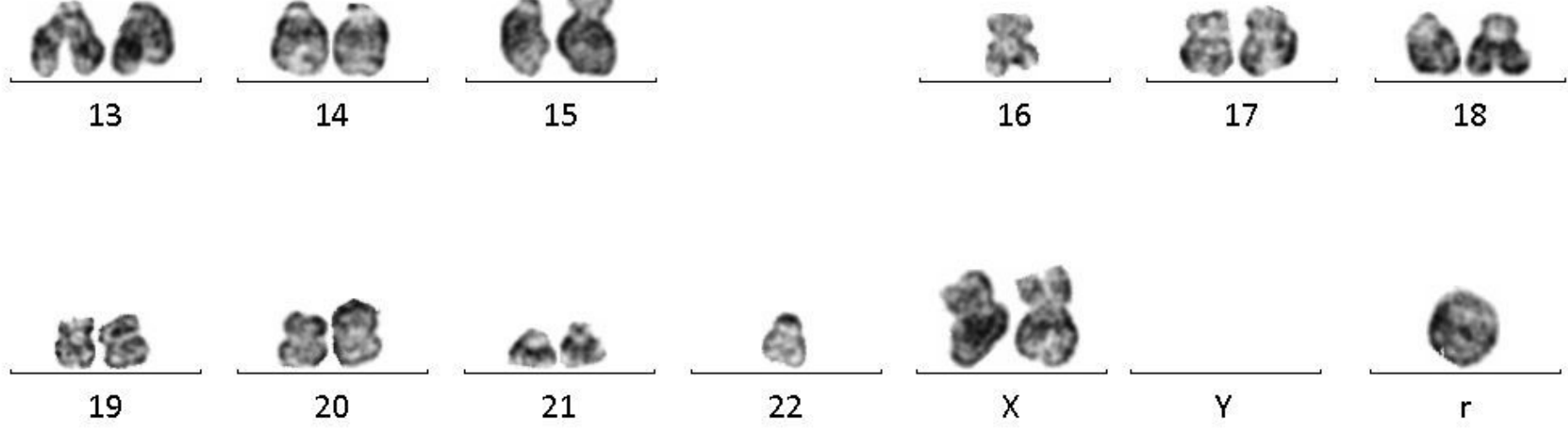

Figure 3

Telomeric association (tas) pattern $(15 ; 22)(p 13 ; p 13)$ 


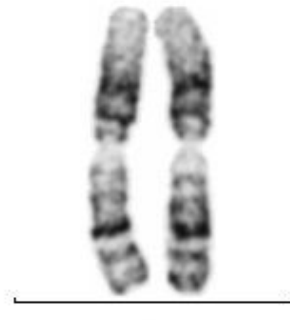

1

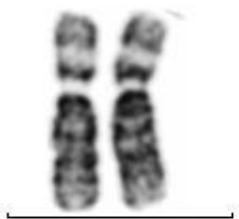

6
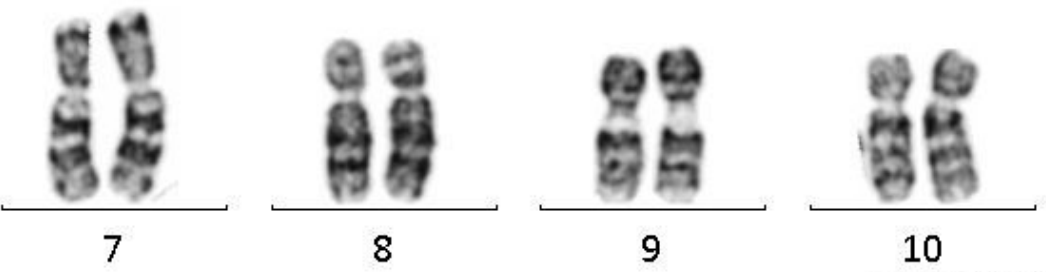

10 $\operatorname{tas}(16 p ; 19 q)$

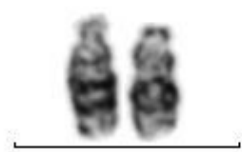

13

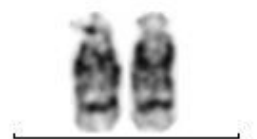

14

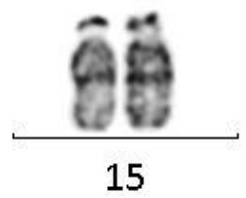

15

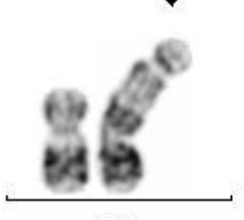

16
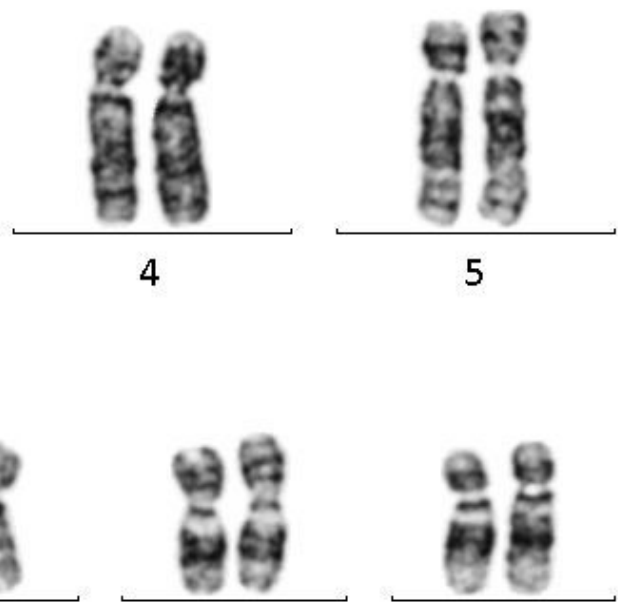

11

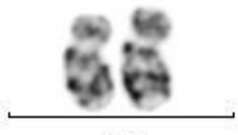

17
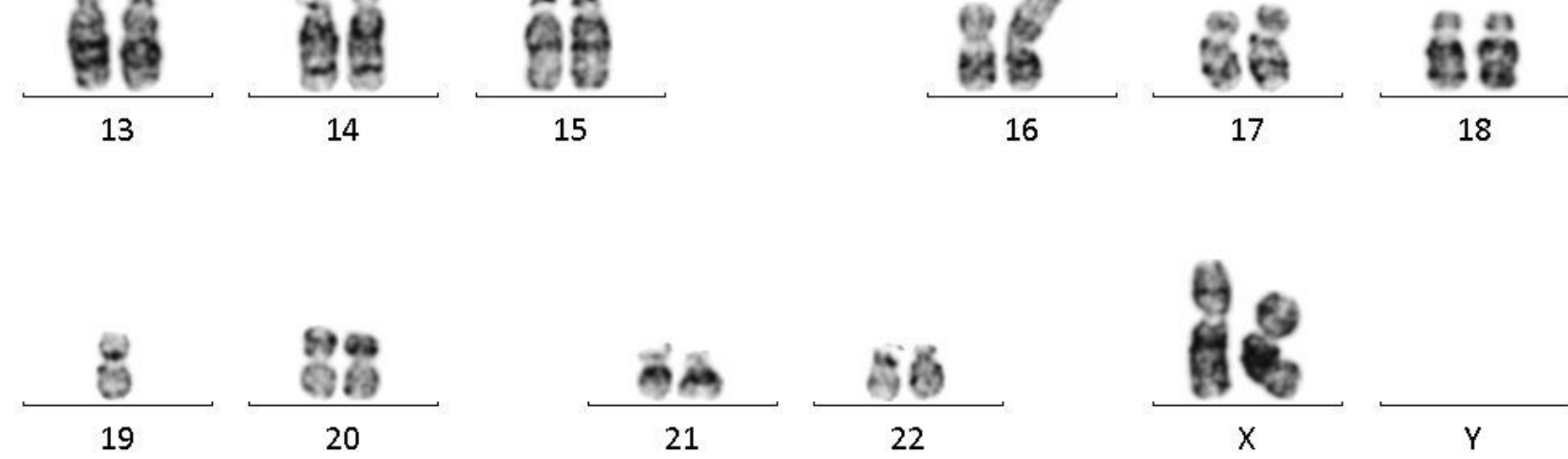

\section{Figure 4}

Telomeric association (tas) pattern (16;19)(p13.3;q13.4) 


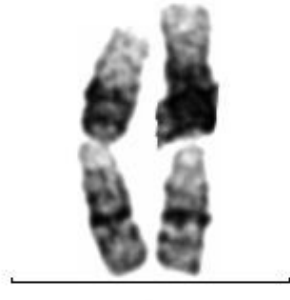

1
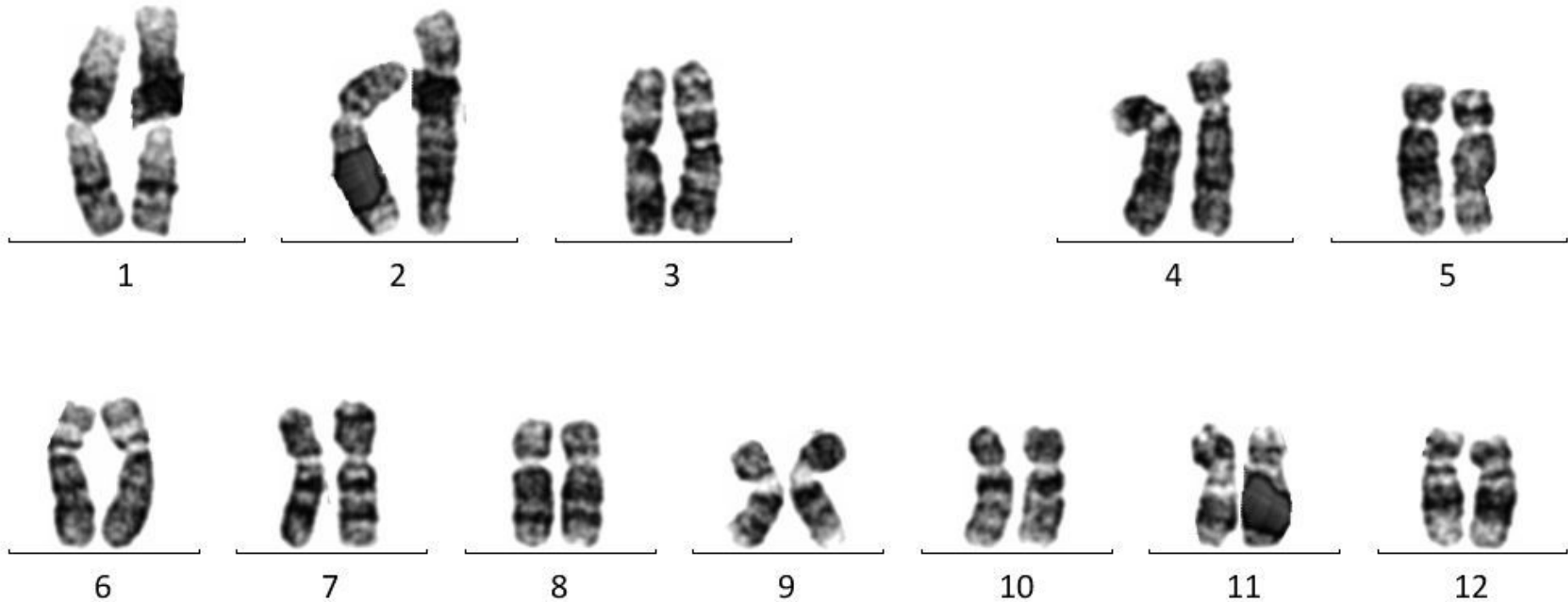

6
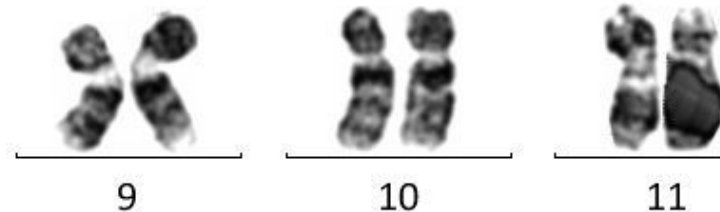

11 $\operatorname{tas}(17 p ; 19 q)$

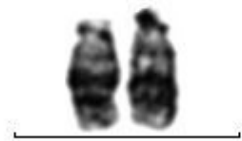

13

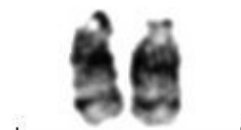

14

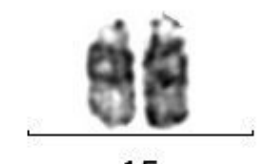

15

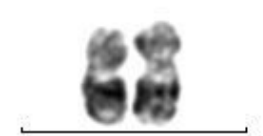

16
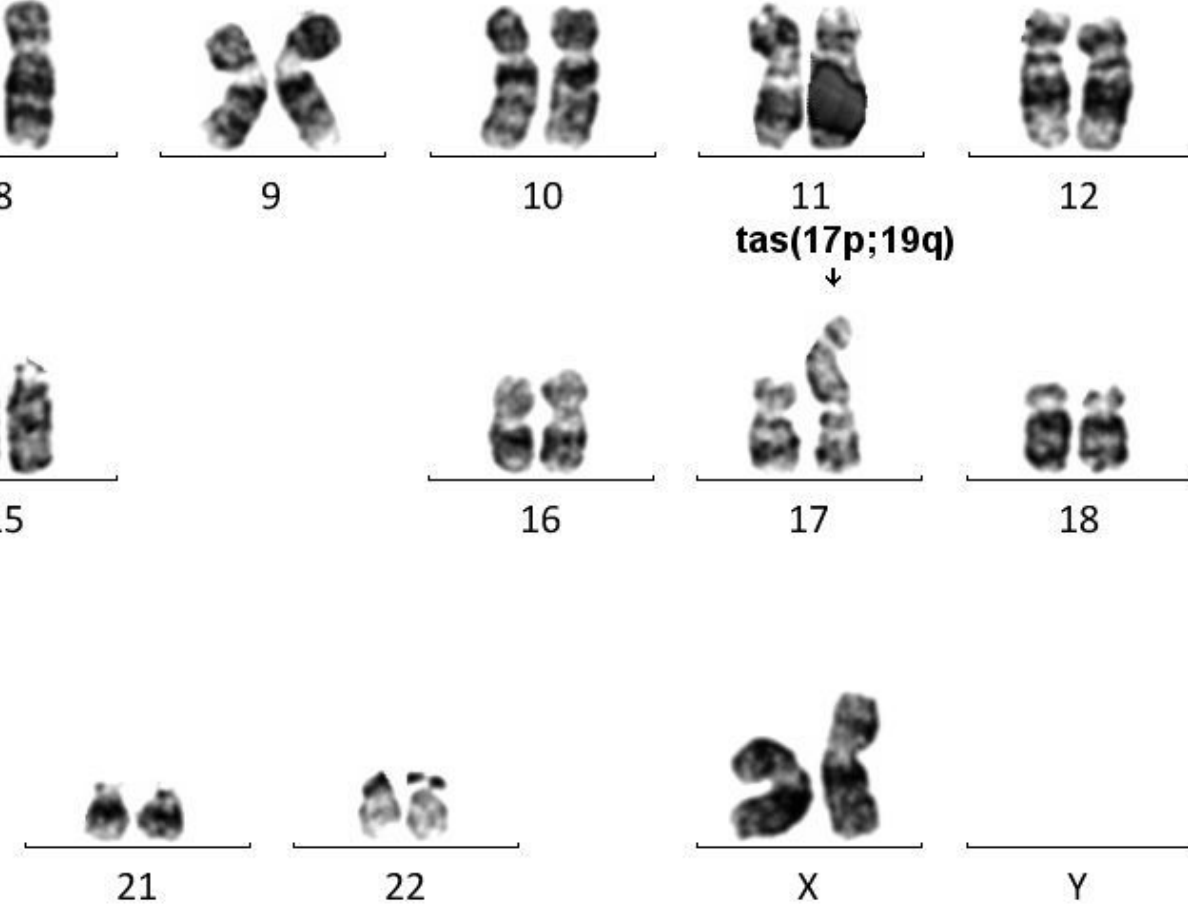

12
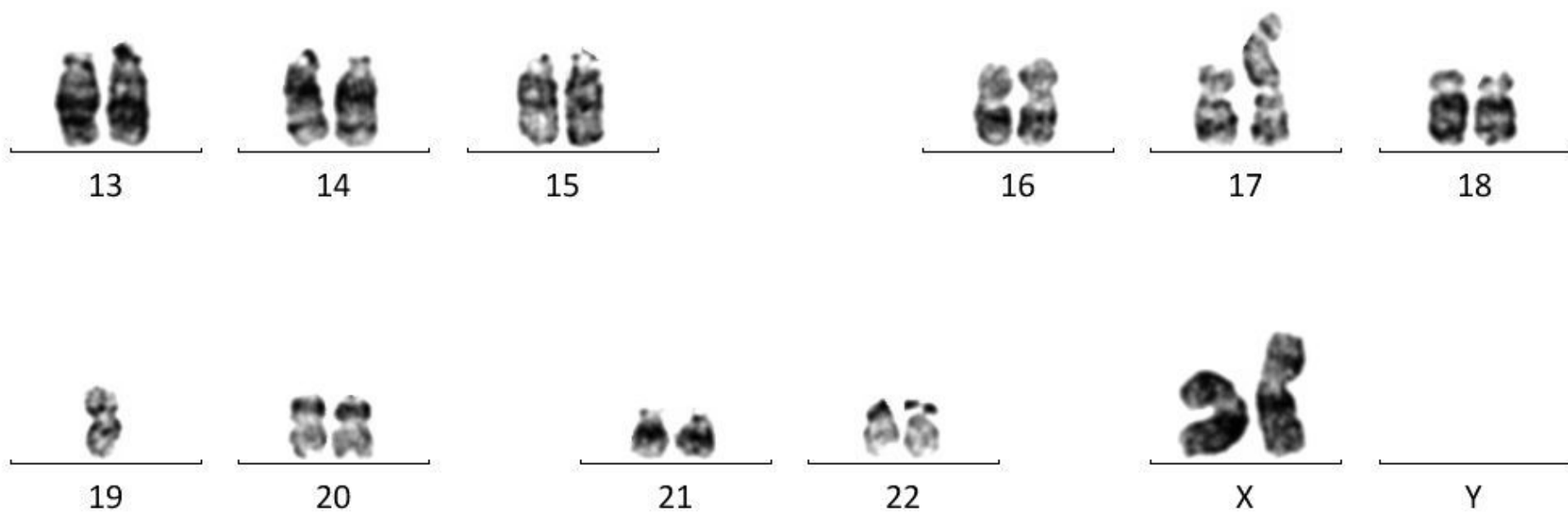

19

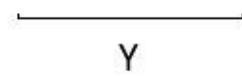

Figure 5

Telomeric association (tas) pattern (17;19)(p13;q13.4) 


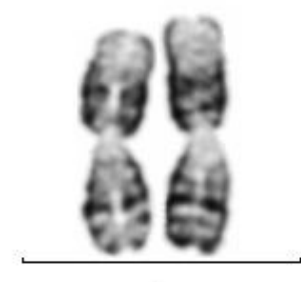

1
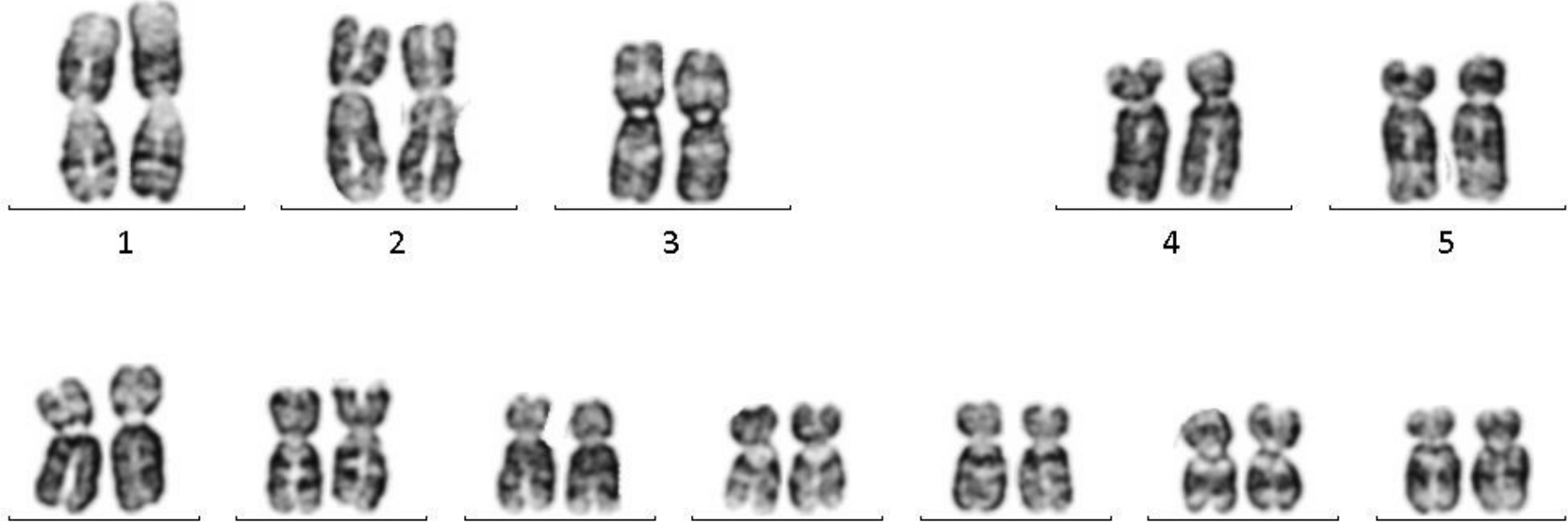

6

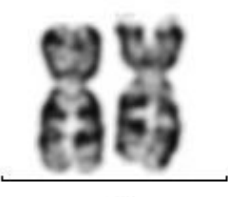

7

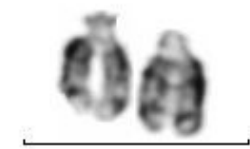

14

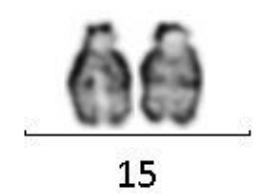

$8 \%$

16
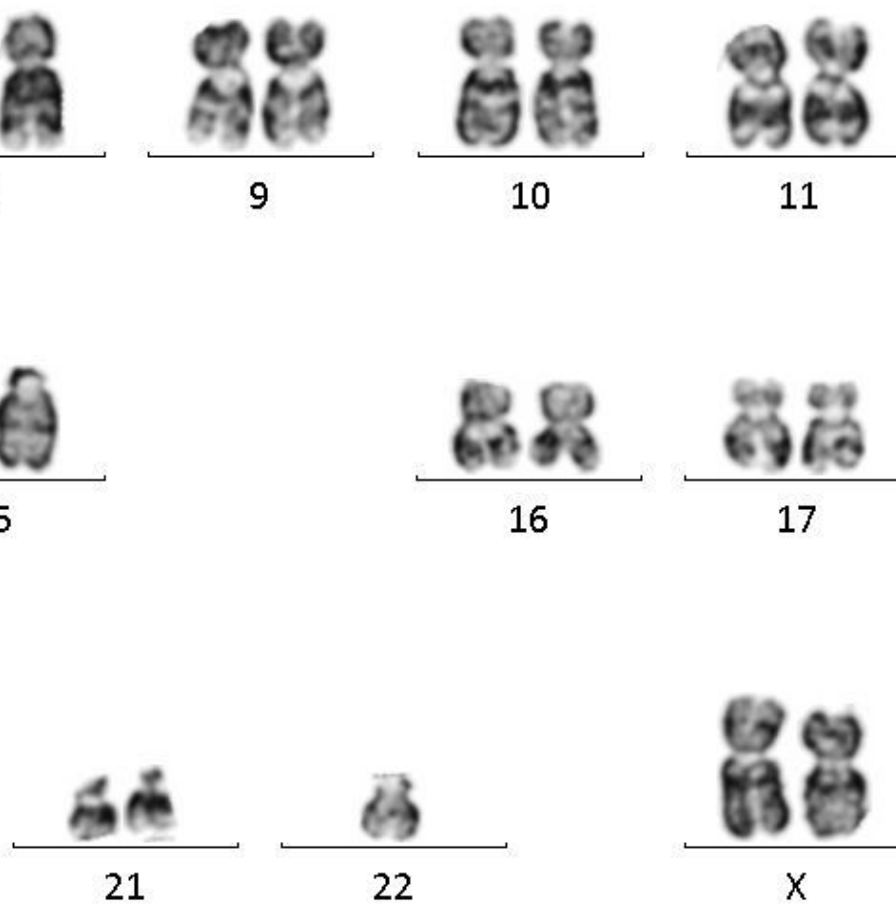

11
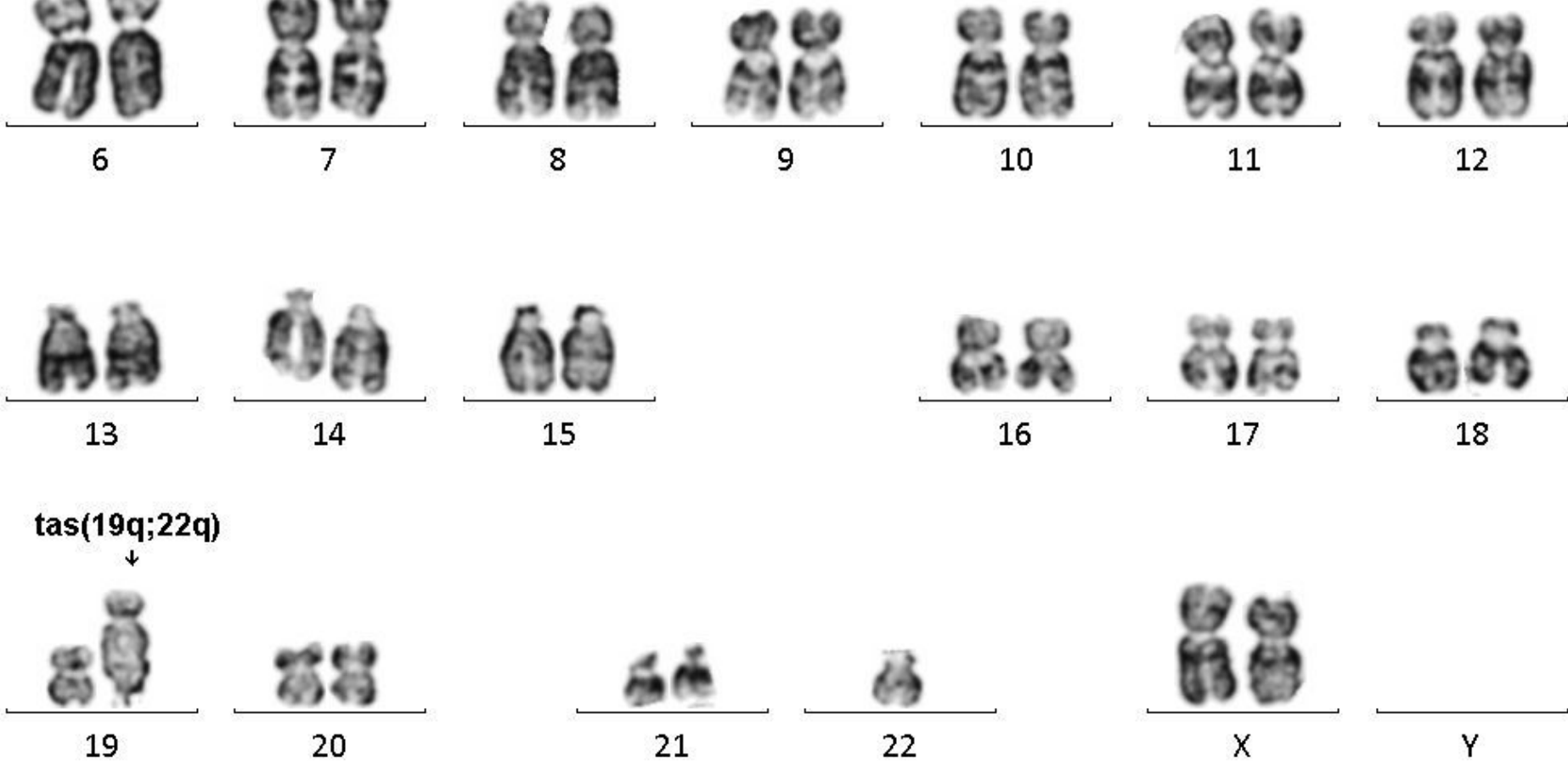

Figure 6

Telomeric association (tas) pattern (19;22)(q13.4;q13)

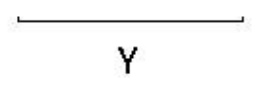

